\title{
Climate change perception
}

\section{and system of rice}

intensification (SRI)

impact on dispersion and

downside risk: a moment

approximation approach

\section{Mintewab Bezabih, Remidius Ruhinduka} and Mare Sarr

November 2016

Centre for Climate Change Economics and Policy Working Paper No. 288

Grantham Research Institute on Climate Change and the Environment

Working Paper No. 256

粦 IDRC $\mid$ CRDI

International Development Research Centre

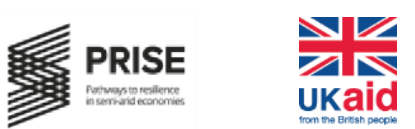


The Centre for Climate Change Economics and Policy (CCCEP) was established by the University of Leeds and the London School of Economics and Political Science in 2008 to advance public and private action on climate change through innovative, rigorous research. The Centre is funded by the UK Economic and Social Research Council. Its second phase started in 2013 and there are five integrated research themes:

1. Understanding green growth and climate-compatible development

2. Advancing climate finance and investment

3. Evaluating the performance of climate policies

4. Managing climate risks and uncertainties and strengthening climate services

5. Enabling rapid transitions in mitigation and adaptation

More information about the Centre for Climate Change Economics and Policy can be found at: http://www.cccep.ac.uk.

The Grantham Research Institute on Climate Change and the Environment was established by the London School of Economics and Political Science in 2008 to bring together international expertise on economics, finance, geography, the environment, international development and political economy to create a world-leading centre for policy-relevant research and training. The Institute is funded by the Grantham Foundation for the Protection of the Environment and the Global Green Growth Institute. It has nine research programmes:

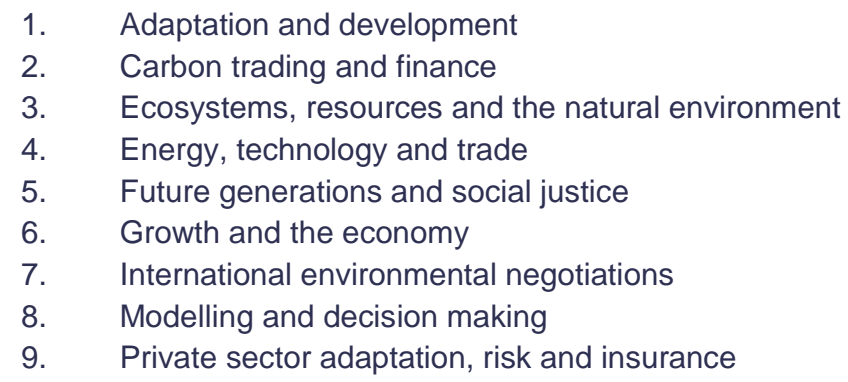

More information about the Grantham Research Institute on Climate Change and the Environment can be found at: http://www.Ise.ac.uk/grantham.

Pathways to Resilience in Semi-arid Economies (PRISE) is a five-year, multi-country research project that generates new knowledge about how economic development in semi-arid regions can be made more equitable and resilient to climate change.

More information about the PRISE project can be found at: www.prise.odi.org.

This working paper is intended to stimulate discussion within the research community and among users of research, and its content may have been submitted for publication in academic journals. It has been reviewed by at least one internal referee before publication. The research for this paper was carried out as part of the PRISE project, under the Collaborative Adaptation Research Initiative in Africa and Asia (CARIAA), with financial support from the UK Government's Department for International Development (DfID) and the International Development Research Centre (IDRC), Canada. The views expressed in this paper are those of the authors and do not necessarily represent those of the host institutions and its funders, including DfID and IDRC or its Board of Governors. 


\title{
Climate Change Perception and System of Rice Intensification (SRI) impact on Dispersion and Downside Risk: A moment Approximation approach
}

\author{
Mintewab Bezabih* $\quad$ Remidius Ruhinduka ${ }^{\dagger} \quad$ Mare Sarr $^{\ddagger}$
}

November 24, 2016

\begin{abstract}
This article assesses the consequential risk impacts of the recent system of rice intensification (SRI) implemented in the Morogoro region of Tanzania, one of the largest Semi-Arid regions, using household and farm plot level data extended to incorporate farmers' perceptions of climate change. The analysis implements a moment approximation approach that accounts for the impacts of the technology on the first three moments of rice yields and total household income. Using a endogenous switching regressions model, we find that perception of climate change is a key driver for SRI adoption and impacts primarily the moments of income. Thereby, the study highlights the importance of climate perceptions and moisture-conserving technology in risk management in Semi-Arid areas. The theme of the study also falls within the objectives of PRISE (Pathways to Resilience in Semi-Arid Economies) as it brings together institutional intervention (in the form of SRI provision), land productivity and vulnerabilit y (in the form of farmers' perceptions of climatic factors).

Key words: SRI adoption; risk, climate change perception; moment approximation, variance, skewness, Tanzania
\end{abstract}

\footnotetext{
*The Grantham Institute for Climate Change and the Environment | London School of Economics and Political Science | Tower $3 \mid$ Clements Inn Passage | London WC2A 2AZ | Email: m.bezabih@lse.ac.uk. Mintewab Bezabih is very grateful for the useful feedback received from Salvatore di Falco, Catherine Simonet and Eva Ludi.

†Department of Economics, University of Dar es Salaam, Tanzania | Email: rremidius@yahoo.com

${ }^{\ddagger}$ School of Economics | University of Cape Town | Private Bag | Rondebosch 7701 | South Africa | Email: mare.sarr@uct.ac.za
} 


\section{Introduction}

The growing literature on climate change predicts that Africa's agrarian economies are likely to disproportionately bear the burden of increased temperature and erratic precipitation through substantial agricultural yield losses (A Dinar, R Hassan, R Mendelsohn, J Benhin - 2012; IPCC, 2007; Kurukulasuriya et al., 2006). Climate change is indeed likely to exacerbate underlying risks associated with climate-dependent economic activities such as rainfed agriculture and to reduce investment under such risky environment (Adger et al. 2003; Moser and Barrett, 2003; Christiaensen and Demery, 2007; Alem et al., 2010). Adaptation strategies are therefore essential to mitigate the adverse consequences of changing climatic conditions. In this context, technologies that raise farmers' crop productivity while improving yield stability are particularly valuable. For instance, many conventional technologies such as those that accompanied the Green Revolution (e.g., improved varieties adoption) often result in greater crop yield but at the expense of increased yield variability and income risk. As Antle and Crissman (1990) demonstrate in a case study of rice production in the Philippines, individual conventional technologies do exhibit risk-enhancing features, although appropriate combinations of management and inputs may achieve lower production risk. In this paper, we assess the impact of an unconventional technology, the system rice intensification (SRI), not only on the mean agricultural yield and household income, but also on their variability and exposure to downside risk, captured by the variance and skewness, respectively.

The system of rice intensification (SRI) was developed in the 1980s in Madagascar as a set of alternative management practices to help poor farmers - who were typically excluded from the input-intensive the Green Revolution-to increase yield, while using cheap organic inputs and reducing water use. Given the inability of most African farmers to access sufficient water resources, irrigation technologies, improved seeds, and inorganic fertilizers due to their cost and due to insufficient rainfall, SRI seems to be the perfect climate change adaptation strategy for these farmers. SRI is based on four principles that rely on an unconventional set of agronomic practices. Unlike the traditional paddy rice cultivation, SRI does not rely on flooding but rather on moist soil, with intermittent irrigations (Stoop, 2002), which is particularly suited in regions where water is a limiting factor. Its guiding principles are: (1) early transplanting (eight to 15 days old) of carefully managed seedlings; (3) single, widely spaced transplants to allow early and regular mechanized weeding; (3) careful and controlled water management; and (4) application of compost to the extent possible (Laulanié, 1993a, b; Stoop, 2002; Noltze et al., 2013). Despite skepticism from the scientific agricultural community, SRI has delivered substantially higher yields while reducing input requirements (less water, seeds and inorganic fertilizers) than the conventional paddy method (Noltze et al., 2013; and Katambara et al., 2013). Furthermore, SRI is reported to produce more robust and resilient crops in the face of extreme weather events, pests and disease (Stoop, 2002; Noltze et al., 2013). As a result, SRI has diffused over the past two decades in the paddy rice growing regions in Asia (e.g., China, India, Vietnam) as well as in Africa. ${ }^{1}$ It is believed that these outstanding outcomes will help poor and vulnerable farmers to increase their yields and incomes while being resilient to the vagaries of unfavorable weather, especially in Africa. However, the spatial diffusion of SRI, the slow adoption rate together with the high rate of dis-adoption among poor farmers has been puzzling (Rakotomalala, 1998; Stoop, 2002; Moser and Barrett, 2003, 2006; Takahashi and Barrett, 2014).

Why would resource-poor rice growers not adopt or even dis-adopt a method that promises to relax the binding constraints they face under the conventional paddy method? Various explanations have been offered. Moser and Barrett $(2003,2006)$ attribute the slow adoption and non-trivial dis-adoption rates to the large hidden opportunity costs of engaging in SRI. Because SRI is a labor-intensive cultivation method, it typically requires a reallocation of paid off-farm labor into family unpaid farm labor to perform time-consuming tasks such as weeding and compost preparation. ${ }^{2}$ For some poor farmers who have very few opportunities to earn cash, the cost is simply too high. ${ }^{3}$

\footnotetext{
${ }^{1}$ By 2015 , SRI has been introduced in no less than 55 countries around the world, among these 22 African countries, including Mali, Nigeria, Tanzania, Kenya, etc.

${ }^{2}$ Weeding is critical in SRI because weeds spread more rapidly under non-flooded conditions (Noltze et al., 2013).

${ }^{3}$ Uphoff (2006) maintains that this is a static view that does not account for the fact that labour intensity diminishes substantially once farmers have become familiar with this new approach.
} 
Besides, since SRI constitutes a set of new, unconventional and un-familiar agronomic practices, success relies heavily on sustained training and extension services. When these services are unavailable or not sustained over time, farmers may have little incentive to adopt SRI. Yet another explanation is that SRI may have impacts beyond the mere average yields and average income. If SRI were to impact the variability of the yields and income, or were to impact the risk of lower yields and lower income then these impacts could also explain this puzzle. Indeed, farmers who are averse to increased variability (risk averse) or averse to increased exposure to downside risk, would abstain from adopting or would dis-adopt SRI despite its potential to deliver higher mean yields and mean income. In this paper, we explore this third and complementary avenue to understand the puzzling low adoption of SRI. Our empirical strategy relies on an endogenous switching regression model that estimates jointly the selection into SRI as well as the effect of SRI on all first three moments of yields and income; that is on expected rice yield and income but also on their variability and exposure to downside risk. This study extends the limited literature on the variance and downside risk effects of technology adoption by focusing on System Rice Intensification (SRI), an integrated technology designed to reduce production risks. By doing so, we move away from the narrowly focused analysis of the sole productivity impacts. For this purpose, a moment-based approach will be developed that will characterize the stochastic technology (Kim and Chavas, 2003; di Falco and Chavas, 2009; di Falco and Veronesi 2014).

The analysis also intends to generate information on the development, dissemination and adoption of agricultural technology in the context of semi-arid areas and along the objectives of PRISE. Specifically as the paper deals with the theme climate vulnerability, land and agricultural growth, the analysis of SRI adoption would contribute to the understanding of its contribution to increasing agricultural productivity per unit of land as well as its features of reducing the dispersion in production as well as its downside risk in poor and risk-prone PRISE settings. Further, the interaction between SRI adoption and climate perception highlights the importance of climate-related in formation in agricultural technology adoption in PRISE regions ${ }^{4}$.

Our analysis highlights the importance of farmers' climate perception both on the adoption decision and on the moments of yield and income. The essence of studying income risk in the context of climate variability stems from the fact that low adaptive capacity implies that risk exposure can be heavily exacerbated by unfavourable climatic conditions (Pecetti et al., 1992; Loss and Siddique, 1994; Di Falco and Chavas, 2009). Hence, in addition to underlying risk considerations, the responsiveness of income risk would depend on climate change and its perceptions.

Analysis of climate change perceptions and its impact on farm level decision making, while recent, is a fast growing area of research. Madison (2007) and Bryan et al. (2009) assessed the ability of farmers in Africa to detect climate change and looked to ascertain how farmers had adapted to whatever climate change they believed had occurred. Their findings show that farmer behavioural responses to perceived climate change tend to be related more to recent climate events or trends as opposed to long-term changes in average conditions (Smit et al., 1997; Granjon, 1999 in Bryant et al., 2000; Thomas et al., 2007; Bryan et al., 2009). In addition, several studies found local knowledge in decision making as it pertains to climate risk to be critical parameter in decision making (Roncoli et al., 2001, 2002; Vogel and O'Brien, 2006; Thomas et al., 2007). Others found that farmers base their decision to adapt their farming practices not only on changes in average conditions, but also on a number of other climate factors observed through personal experience such as extreme events, rainfall frequency, timing, and intensity, and early or late frosts, highlighting the importance of climatic perceptions (Smithers and Smit, 1997; Roncoli et al., 2002; Vogel and O'Brien, 2006; Thomas et al., 2007). ${ }^{5}$

Our analysis is most closely related to the following studies. Alem et al. (2015) find positive impacts of SRI on

\footnotetext{
${ }^{4}$ PRISE focused countries are Senegal, Burkina Faso, Tanzania, Kenya, Pakistan and Tajikistan

${ }^{5} \mathrm{~A}$ number of studies point to bias in the perception of climate change associated with different factors. In line with this, Howe and Leiserowiz (2013) find that the subjective experience of local climate change is dependent not only on external climate conditions, but also on individual beliefs, with perceptions apparently biased by prior beliefs about global warming. In addition, Whitmarsh (2011) argues that individual attitudes and biased cognitive processing can also bias information recall associated with climate change. Similarly, Weber (2010) argues that recent events are likely to be given more weight than distant events in the evaluation of risky options.
} 
crop yield with the emphasis that its impact on farm profit hinges on the actual market price faced by the SRI farmers. However, their analysis does not analyse the role of climate perception in the adoption of SRI as well as it's the welfare impacts of such perceptions. In terms of closely analyzing the role of climate perception in technology adoption in the context of Africa, Teklewold et al. (2015); Difalco and Veronsi (2013), and Difalco et al. (2011) are worth mentioning. However the analysis in the latter two studies focuses on a range of adaptation techniques excluding the adoption of modern improved varieties like the SRI. Our study therefore brings to light an important oversight in the literature by looking into the role of climate perception in risk reduction when the specific technology under consideration is believed to be risk-reducing.

The rest of the paper is organized as follows. In section 2, we present some background description about SRI adoption and climate change in Tanzania. The survey strategy and data are discussed in section 3 , while the estimation methodology is provided in section 4. Section 5 presents the empirical findings and section 6 concludes the paper.

\section{Background: Climate change and SRI adoption in Tanzania}

Vulnerability of rainfed agriculture to climate change could have devastating consequences for the welfare of smallholder farmers in Tanzania due to reduced agricultural yields. Recent findings suggest that climate change may yield shorter growing seasons and stress on cash crops due to increased moisture, heat, insects and pests (Mongi, et al., 2010), resulting in likely deteriorations in food security (Arndt et al., 2011). In that regard, Rowhani et al. (2010) show that a $2^{\circ} \mathrm{C}$-rise in temperature by 2050 may induce a decline in mean yields of maize, sorghum and rice by $12 \%, 8.8 \%$ and $7.6 \%$, respectively.

The impact of climate change on Tanzanian agriculture will not only be influenced by mean changes in climatic conditions, but also by its associated variability. For instance, Rowhani et al. (2010) argue that ignoring climate variability indeed underestimates the decline in maize, sorghum and rice yields by $3.6 \%, 8.9 \%$, and $28.6 \%$, respectively. Moreover, Ahmed et al. (2011) find high yield variability of staple grains to be associated with large increases in poverty. However, in analyzing the economy-wide effects of climate change in Tanzania, Bezabih et al. (2011) contend that despite the projected reduction in agricultural productivity, the negative impacts may be fairly limited provided policies that enable farmers to respond appropriately to changes in climatic conditions are implemented.

Policies promoting adoption of technologies that contribute to farmers' adaptation to climate change and climate variability are of particular interest in this regard. However, in addition to their costliness, conventional yieldenhancing technologies (e.g., improved varieties, cultivation of paddy rice, etc.) may be unsuitable for poor and vulnerable farmers whenever they lead to a rise in yield variability and to greater exposure to downside risk (Kim and Chavas, 2003), especially in a context of changing climatic conditions. For instance, in Tanzania, the conventional flooding techniques in paddy fields are deemed inefficient given limited water availability and growing seasonal variability (Katambara et al., 2013). The recent introduction of the system of rice intensification (SRI) in 2006 aimed to lessen the water intensity of rice production, improve low yields and consequently increase farmers' incomes. Crops cultivated under SRI are also reported to be more resilient in the face of extreme weather events, pests and diseases. This novel and unconventional approach seems particularly suited to poor farmers in water scarce regions because it requires reduced inputs (less water, less seeds and less inorganic fertilizers are needed). A simplified variant of the SRI developed in Madagascar has been introduced in Tanzania since 2006. It entails shallow planting of 1-2 cm of transplanted seedlings aged 8 to 12 days on a square grid of $20-25 \mathrm{~cm}$ with intermittent irrigation, fertilizer and weeding (Nakano et al., 2014; Africare, 2010; Katambara et al., 2013b). The SRI was implemented in several regions of Tanzania and has met some success regarding yields improvement, water efficiency, productive tillers and panicles requirements of rice production (Katambara et al., 2013a). For example, in Mkindo (Morogoro Province) water efficiency improved by up to $64 \%$ while yields increased from 3.8 tons/ha (with conventional methods) to 6.3 tons/ha (Katambara et al., 2013a). In addition, wider spacing and less transplanted seedlings (up 
to $10 \mathrm{~kg}$ /ha less seeds), as well as decreased disease vulnerability and enhanced wind resiliency due to healthier and more robust plant stems and lowered expected soil erosion (Katambara et al., 2013a). Despite these seemingly promising results, adoption of SRI has been limited in Tanzania (Katambara et al., 2013a). In the following sections, we investigate the determinants of SRI adoption in the Morogoro region of Tanzania as well as the effect of adoption on the first three moments (mean, variance and skewness) of agricultural yield and farmer's income.

The study area focuses on one of the semi-arid regions of the country, the Morogoro region Mahoo et al., 1999). As project 5 of PRISE is focused on land, climate change, land productivity and risk responsiveness in the context of Semi-Arid areas, this study could be considered as a relevant contribution to the project. The study is of importance to PRISE for three major reasons. First, assessment of technology options with environmentally sensitive features such a SRI is rare in the African context. Second, in such a rain-fed setting, any significant variation in the temporal and spatial distribution of rainfall usually is manifested in a serious moisture constraint (Bezabih et al., 2011; Mahoo et al., 1999). Indeed, existing literature on technology adoption and its impact on welfare typically focuses on technological, informational, resource and institutional constraints, with rare focus on agroecological differences (exceptions include Kassie et al., 2010). Third, as semi-arid areas are sensitive to the vagaries of climate, assessing the impact of climatic perceptions in the adoption of the technology and on its different outcome features enables understanding the dynamics of climate-perception and technology adoption in such settings, also generates valuable information.

\section{Data}

The data used for the empirical analysis is based on a survey in the Kilombero district of Morogoro region, one of the largest rice producing regions in the country. In this district, 334 rice farming households were randomly selected from eight villages for the farming season ending in June, 2013. In the Tanzanian setting, an SRI package consists of seeds sorting prior to planting, square grid planting, use of saro seeds varieties, and application of chemical fertilizers. We consider a household to be SRI adopter if it applies at least three of the four components. However, none of these components is applied universally by all adopting households, which underscores the fact that SRI adoption is partial. ${ }^{6}$

The choice of plots that were allotted to SRI occurred as follows. Initially, farmers gave information on all of their rice-planted plots in the survey year, by SRI status. It was noted that multiple plots cultivation was only common among the traditionally farmed varieties but not on SRI. Whenever a household adopted SRI it only applied the method in one of its plots and not in several, hence our choice of only one plot for the SRI. For the non-SRI plots, a representative plot was selected using a simple random technique in order to minimize minimize the plot-level selection bias for this particular category of plots. In Section 4, we discuss the econometric steps we took to further control for potential selection bias resulting from systematic selection of plots into the SRI and non-SRI categories.

With an adoption rate of approximately $60 \%$, a total of 193 households have adopted SRI on at least one of their plots during the previous agricultural season. When a household operates several plots, information is collected only for one randomly selected plot. The survey includes detailed socio-economic households characteristics, plotspecific information, as well as farming inputs used (from plots preparation to the post-harvest), alongside output and marketing information. Table 1 below presents the mean of the variables used in the regressions by SRI adoption status, as well as the mean differences between the adopter and non-adopter groups.

On average, households adopting SRI tend to be larger, headed by older farmers (44.5 versus 41 years for nonadopters) and have more males of a working age (i.e., 15 years and above). They are typically wealthier, have more experience in rice farming and a denser social network. They also tend to receive visits from extension services.

\footnotetext{
${ }^{6}$ Each of the components is applied on almost 90 percent of the adopting plots. This is comparable to related studies (e.g.. Noltze et al, 2013; Takahashi and Barrett, 2013).
} 
These differences are statistically significant at least at the 5 percent level. However, we do not find any statistically significant differences across the two groups when it comes to their level of education and marital status.

Farmers typically practice SRI on relatively smaller plots ( 1 acre compared to 2.8 acres) that are located closer to their homesteads $(3.7 \mathrm{~km}$ vs. $4.7 \mathrm{~km})$. On average, these plots are more fertile than the conventionally cultivated plots. However, we do not find any significant differences across plots on other observable characteristics such as slope and soil type.

Consistent with previous literature, practising SRI requires considerably more labor. On average an SRI plot requires almost twice as much labor supply (64 man-days vs. 33 man-days for non-SRI plots) This substantial difference emphasizes the need of evaluating the impact of the technology beyond mere agricultural yield given both the direct and indirect costs of such extra labor requirement. In addition, given the potential reallocation of labor by SRI farmers from other income generating activities to SRI plots, assessing the higher moments impact of the technology becomes even more important since the adopting household in this case has less window to diversify against bad outcome risks.

The key dependent variables, in addition to SRI adoption, are yield and total household income. Yield is calculated as total harvest per acre of cultivated land in thousands of tonnes. Given the labor intensive nature of SRI, it is important to estimate its impact on total households' income, accounting for both direct and indirect costs associated with such extra labour demand. Because the adoption of SRI requires additional labor supply (expressed in mandays), it could be the case that increased labor costs could negatively affect both farm and off-farm incomes. Total household income constitutes both total farm profit and off-farm earnings from all sources including remittances within the same agricultural season. Farm income is calculated as difference between total revenue and total production cost per acre, multiplied by total size of the cultivated plot. While revenue is computed as the product of farm gate price of paddy per kilogram and yield, we calculate total cost as the sum of all input costs (including seeds, labor, herbicides and fertilizer) used during the entire farming year starting from plot preparation to the harvest period. It should be noted that Labor cost constitutes of both household labor (computed using shadow wage approach by Jacoby, 1993) and cost for hired labor. Preliminary assessment suggests that SRI farmers obtain significantly more yield, and total household income than their counterparts. On average, SRI farmers harvest 7.51 in $\log \mathrm{kg}$ per acre and earn a total income of TZS 1.6 million compared to a yield of 6.85 (log $\mathrm{kg}$ per acre) and an income of TZS 1.2 million for non-adopters.

Finally, households were also asked about their perception regarding changing climatic patterns-average annual rainfall and temperature-over the past 10 years. Perception about climate change is captured by two dummy variables that indicate whether a farmer has noticed a pattern of rising average temperatures or declining rainfalls over the past decade. These dummy variables are constructed based on farmers' direct response. Most farmers have perceived such changing patterns; nearly $60 \%$ of SRI adopters have observed a decrease in the average rainfall, as opposed to $53 \%$ of the non-adopters, although the difference is not statistically significant. Approximately, $64 \%$ of both SRI adopters and non-adopters believe that average annual temperatures are increasing.

It is however important to note that due to self-selection problem (or endogeneity bias) we cannot attribute all the differences presented in the table to SRI adoption. Given that SRI farmers are more socially connected, receive more extension services and that they apply the technology on more fertile plots, adopters and non-adopters could still have some outcome differences even without the technology adoption.

\section{Conceptual framework and econometric methodology}

The premise of our analysis is that farmers are expected to grow yield-enhancing varieties such that welfare is improved from the gains of higher yields and profit. Further, to the extent that SRI is perceived and conceived as a risk mitigating practice, it is expected to have additional welfare benefits to generally poor and risk-averse farmers (Kim and Chavas, 2003). Our analysis relies on a moment-based specification of the stochastic production function 
Table 1: Summary Statistics

\begin{tabular}{|c|c|c|c|c|}
\hline \multirow{2}{*}{ Variables } & \multicolumn{2}{|c|}{ Entire sample } & \multicolumn{2}{|r|}{ Sub-samples } \\
\hline & Mean & Std dev & Mean Adopters & Mean Non-Adopters \\
\hline Age & 42.96 & 11.87 & 44.46 & 40.91 \\
\hline Household size & 4.71 & 1.84 & 4.91 & 4.44 \\
\hline Married (dummy) & 0.86 & 0.35 & 0.87 & 0.85 \\
\hline Male (dummy) & 0.91 & 0.29 & 0.89 & 0.94 \\
\hline Men & 1.51 & 0.91 & 1.56 & 1.43 \\
\hline Education (in years) & 7.00 & 1.88 & 7.04 & 6.94 \\
\hline Experience rice (in years) & 14.91 & 9.72 & 15.65 & 13.90 \\
\hline Wealth (log wealth) & 12.72 & 1.25 & 12.89 & 12.49 \\
\hline Total labor supply (in man days) & 50.84 & 68.83 & 63.62 & 33.36 \\
\hline Chemical fertilizer usage (dummy) & 0.54 & 0.50 & 0.86 & 0.09 \\
\hline Plot size (in acre) & 1.74 & 2.33 & 0.97 & 2.78 \\
\hline Very fertile & 0.41 & 0.49 & 0.41 & 0.40 \\
\hline Fertile & 0.92 & 0.28 & 0.95 & 0.87 \\
\hline Slopy plot & 0.13 & 0.34 & 0.11 & 0.16 \\
\hline Plot distance (in km) & 4.10 & 4.39 & 3.75 & 4.58 \\
\hline Distance to market (in km) & 87.54 & 203.19 & 102.8 & 66.67 \\
\hline Agriculture as main activity & 0.96 & 0.19 & 0.97 & 0.94 \\
\hline Yield (in log kg per acre) & 7.23 & 0.83 & 7.51 & 6.85 \\
\hline Total Income (in million TZS) & 1.39 & 2.00 & 1.58 & 1.12 \\
\hline Extension (dummy) & 0.43 & 0.50 & 0.62 & 0.16 \\
\hline Perception Rain decrease (dummy) & 0.57 & 0.50 & 0.60 & 0.53 \\
\hline Perception Temperature increase (dummy) & 0.64 & 0.48 & 0.64 & 0.65 \\
\hline Years in the village & 14.19 & 9.91 & 15.27 & 12.70 \\
\hline Social connection & 0.87 & 0.30 & 0.94 & 0.78 \\
\hline Sort seed & 0.72 & 0.45 & 0.92 & 0.45 \\
\hline Number of observations & 334 & 334 & 193 & 141 \\
\hline
\end{tabular}


(Antle 1983; Antle and Goodger 1984). The method has been widely used in the context of risk management in agriculture (Just and Pope 1979; Kim and Chavas 2003; Koundouri et al. 2006; and Di Falco and Chavas 2009). It is based on Pratt's (1964) concept of risk premium as a measure of the cost of private risk bearing, where technological progress may potentially be either risk-increasing or risk-decreasing depending on whether it increases or decreases the relative risk premium. As a result, the welfare of risk averse farmers may be adversely affected by mean-preserving increases in the variance of yield or income and in the associated skewness (e.g. the probability of crop failure). Since increased variance does not distinguish between unexpectedly good and bad events, and since the avoidance of crop failure is the major objective of farmers in Sub-Saharan Africa (Di Falco and Chavas, 2009), the notion of skewness is particularly important. While, risk averse farmers may have an incentive to reduce the variance of returns, farmers exhibiting aversion to downside risk have an incentive to grow varieties that positively affect the skewness of the distribution of returns, thus reducing their exposure to downside risk (e.g. severe drought leading to crop failure) (Kim and Chavas, 2003; Difalco and Chavas, 2009). Thus, a moment-based approach can capture the full extent of risk exposure.

We therefore estimate the impact of the new technology (SRI) on outcome variables between adopters and nonadopters, beyond the usual mean difference to also assess its impacts on higher moments of the outcome variables (i.e. variance and skewness). Our empirical approach addresses two estimation considerations. First, there is a potential problem of simultaneity bias because although adoption of SRI may result in enhanced yields and higher incomes, it can also be the case that higher yields and incomes increase the probability of adopting SRI. Second, some observed and unobserved characteristics (household or farm characteristics) may concurrently affect both selection (adoption of SRI) and outcome (income or yield). Estimation of the effects of adoption via ordinary least squares (OLS), which assumes random selection, is therefore potentially biased.

Standard treatment effects models typically include a treatment dummy as explanatory variable, assuming that the impact on the outcome variable can be represented as a simple intercept shift. Noltze et al (2013) argue that this is inappropriate because farm and farmer conditions may systematically influence SRI impacts on yields and household incomes. Following previous studies (e.g., Di Falco et al, 2011; Noltze et al, 2013), we employ an endogenous switching regression model (ESR) to address this estimation bias. Apart from its ability to correct for selection bias due to observable and unobservable differences between the groups, ESR allows us to estimate both the average treatment effects on the treated (ATT) and the average treatment effect on the untreated households (ATU). The endogenous switching regression model consists of two stages. The first stage is a selection equation that is based on a dichotomous choice function (probability of adopting SRI), while the second stage, the outcome equations, feature the determinants of the outcome equations (yield or income) for both adopters and non-adopters.

In the first stage, given observed and unobserved characteristics, each farmer elects to adopt the new SRI technology or not whenever his latent (unobserved) expected benefits from adoption $\left(S R I^{*}\right)$ are positive, and will abstain otherwise. The decision to adopt is however observed and captured dummy variable $S R I$ which takes value 1 in case of adoption. The first stage selection equation is typically modeled as follows:

$$
\begin{aligned}
& S R I_{i}^{*}=S_{i}^{\prime} \gamma+v_{i} \\
& S R I_{i}= \begin{cases}0 & \text { if } S R I_{i}^{*} \leq 0 \\
1 & \text { if } S R I_{i}^{*}>0\end{cases}
\end{aligned}
$$

where $S_{i}$ is a vector of exogenous variables affecting both the probability of adopting SRI. These variables include $(i)$ households' characteristics such as education, age, marriage status, experience, and wealth; (ii) farm characteristics such as farm size, fertility of the soil, and slope of the terrain; (iii) social network and training; and (iv) perception about changing climatic patterns, which is a novelty in the SRI literature (see for example Takahashi and Barrett, 
2013; Noltze et al, 2013).

The second stage outcome equations are explicitly modeled differently according to the farmers' adoption decision. The model accommodates the two adoption regimes:

$$
\begin{aligned}
& \text { Regime 0: } y_{0 i}=X_{i}^{\prime} \beta_{0}+\varepsilon_{0 i} \text { if } S R I_{i}=0 \\
& \text { Regime 1: } y_{1 i}=X_{i}^{\prime} \beta_{1}+\varepsilon_{1 i} \text { if } S R I_{i}=1
\end{aligned}
$$

where $y_{0 i}$ and $y_{1 i}$ denote the values of the outcome (mean, variance and skewness of yield, profit and income) for farm household $i$ in each adoption regime; $X_{i}$ is a vector of exogenous covariates that influence the outcome in each regime, and $\beta_{0}$ and $\beta_{1}$ are the associated vectors of coefficients. This method allows for correlation between the three error terms $\varepsilon_{0 i}, \varepsilon_{1 i}$ and $v_{i}$-which are assumed to be jointly normally distributed $\mathcal{N}(0, \Sigma)$ where the covariance matrix is written as:

$\Sigma=\left[\begin{array}{ccc}\sigma_{v}^{2}=1 & \sigma_{0 v} & \sigma_{1 v} \\ \sigma_{0 v} & \sigma_{0}^{2} & \cdot \\ \sigma_{1 v} & \cdot & \sigma_{1}^{2}\end{array}\right]$.

The covariance terms between $\varepsilon_{0 i}$ and $\varepsilon_{1 i}$ are not defined (.) since a given farmer cannot be simultaneously an adopter and a non-adopter. The first variance $\sigma_{v}^{2}$ is normalized to one to ensure statistical identification of parameters.

We typically estimate this endogenous switching regression model by using a consistent and efficient procedure that relies on full information maximum likelihood (FIML) with observation $i^{\prime} s$ likelihood written as follows:

$$
\begin{aligned}
\mathcal{L}_{i} & =\operatorname{Pr}\left(y_{i} \text { and } S R I_{i}=\{0,1\}\right) \\
& =\left[\operatorname{Pr}\left(y_{i}=y_{1 i}, S R I_{i}=1\right)\right]^{S R I_{i}} \cdot\left[\operatorname{Pr}\left(y_{i}=y_{0 i}, S R I_{i}=0\right)\right]^{1-S R I_{i}} \\
& =\left[\operatorname{Pr}\left(y_{i}=y_{1 i}\right) \operatorname{Pr}\left(S R I_{i}=1 \mid y_{i}=y_{1 i}\right)\right]^{S R I_{i}} \cdot\left[\operatorname{Pr}\left(y_{i}=y_{0 i}\right) \operatorname{Pr}\left(S R I_{i}=0 \mid y_{i}=y_{0 i}\right)\right]^{1-S R I_{i}}
\end{aligned}
$$

where

$$
\begin{gathered}
\operatorname{Pr}\left(y_{i}=y_{j i}\right)=\operatorname{Pr}\left(y_{i}=X_{i}^{\prime} \beta_{j}+\varepsilon_{j i}\right)=\frac{1}{\sigma_{j}} \phi\left(\frac{y_{i}-X_{i}^{\prime} \beta_{j}}{\sigma_{j}}\right) \\
\operatorname{Pr}\left(S R I_{i}=1 \mid y_{i}=y_{j i}\right)=\operatorname{Pr}\left(v_{i} \mid \varepsilon_{j i}=\varepsilon_{j 0}>-S_{i}^{\prime} \gamma\right)=\Phi\left(\frac{S_{i}^{\prime} \gamma+\rho_{j v}\left(y_{i}-X_{i}^{\prime} \beta_{j}\right) / \sigma_{j}}{\sqrt{1-\rho_{j v}^{2}}}\right) \\
\operatorname{Pr}\left(S R I_{i}=0 \mid y_{i}=y_{j i}\right)=\operatorname{Pr}\left(v_{i} \mid \varepsilon_{j i}=\varepsilon_{j 0} \leq-S_{i}^{\prime} \gamma\right)=1-\Phi\left(\frac{S_{i}^{\prime} \gamma+\rho_{j v}\left(y_{i}-X_{i}^{\prime} \beta_{j}\right) / \sigma_{j}}{\sqrt{1-\rho_{j v}^{2}}}\right)
\end{gathered}
$$

where $\phi$ and $\Phi$ are the standard normal probability density and cumulative distribution functions; and $j=0,1$ represents SRI adaptation and non-adaptation, respectively.

For proper identification of the selection equation coefficients, we assume at least one element of the vector of covariates $S$ in the SRI equation is excluded from the outcome equations. Our exclusion restriction relies on two sets of variables. First, we rely on variables relating to social network (density of the connection and number of years in the village) which as we will see do not affect the outcome directly but through SRI adoption decision. Secondly, as another excluded variable, we include a variable that captures a management practice that is closely associated with SRI. For instance, the practice of sorting seeds is particularly advocated within SRI. We can presumably assume that this activity will affect yield or income (mean, variance and skewness) only through SRI and not 
directly. The admissibility of the instruments is tested by performing the falsification test introduced by di Falco et al. (2011). That is, a valid set of instruments will affect the decision to adopt SRI but not the moments of yield or income for non-adopters. As we show in Panel $\mathrm{C}$ of Tables 2 and 3, based on the admissibility tests, we can never reject the null that the chosen instruments are valid.

As noted before, following Kim and Chavas (2003), we estimate our switching models (for total harvest and total income) considering not only the mean levels as dependent variables, but also the variance, to capture variability, and the skewness, to capture exposure to downside risk. Considering the variance and its skewness in addition to its levels, allows us to identify potential trade-offs between productivity gains and income stability (the risk of income loss /crop failure). For example, if we consider regime 1, the second and third moments (variance and skewness) are calculated as:

$$
\begin{aligned}
\text { Variance } & =\mu_{2 y_{1}}=\mathbb{E}\left[\left(y_{1}-\mathbb{E}\left(y_{1}\right)\right)^{2}\right] \\
\text { Skewness } & =\mu_{3 y_{1}}=\mathbb{E}\left[\left(y_{1}-\mathbb{E}\left(y_{1}\right)\right)^{3}\right]
\end{aligned}
$$

To compare differences in total yield and total income between adopter and non-adopter households, we calculate treatment effects using estimates from the switching regression models. Two effects are of particular interest. First, we estimate the effect of treatment on adopters or treated (i.e., ATT); that is, the effect of adoption on adopters. Secondly, we estimate the effect of treatment in the non-adopter or untreated (i.e., ATU); that is, the effect of adoption on non-adopters had they adopted SRI). The unbiased treatment effects ATT and ATU that control for observed and unobserved heterogeneity are given by:

$$
\begin{aligned}
& A T T=\mathbb{E}\left(y_{1 i} \mid S R I_{i}=1\right)-\mathbb{E}\left(y_{0 i} \mid S R I_{i}=1\right) \\
& A T U=\mathbb{E}\left(y_{1 i} \mid S R I_{i}=0\right)-\mathbb{E}\left(y_{0 i} \mid S R I_{i}=0\right)
\end{aligned}
$$

where

$$
\begin{aligned}
& \mathbb{E}\left(y_{1 i} \mid S R I_{i}=1\right)=X_{i}^{\prime} \beta_{1}+\lambda_{1} \sigma_{1 v} \\
& \mathbb{E}\left(y_{0 i} \mid S R I_{i}=1\right)=X_{i}^{\prime} \beta_{0}+\lambda_{1} \sigma_{v 0} \\
& \mathbb{E}\left(y_{1 i} \mid S R I_{i}=0\right)=X_{i}^{\prime} \beta_{1}+\lambda_{0} \sigma_{v 0} \\
& \mathbb{E}\left(y_{0 i} \mid S R I_{i}=0\right)=X_{i}^{\prime} \beta_{0}+\lambda_{0} \sigma_{1 v}
\end{aligned}
$$

The inverse mills ratios $\lambda_{0}$ and $\lambda_{1}$ evaluated at $S_{i}^{\prime} \gamma$ characterize the truncated error terms so that:

$$
\begin{aligned}
& \mathbb{E}\left(\varepsilon_{1 i} \mid v_{i}>-S_{i}^{\prime} \gamma\right)=\frac{\phi\left(S_{i}^{\prime} \gamma\right)}{\Phi\left(S_{i}^{\prime} \gamma\right)} \sigma_{1 v}=\lambda_{1} \sigma_{1 v} \\
& \mathbb{E}\left(\varepsilon_{0 i} \mid v_{i} \leq-S_{i}^{\prime} \gamma\right)=\frac{\phi\left(S_{i}^{\prime} \gamma\right)}{1-\Phi\left(S_{i}^{\prime} \gamma\right)} \sigma_{0 v}=\lambda_{0} \sigma_{0 v}
\end{aligned}
$$

\section{Results and discussion}

We estimate the impact of SRI on the first three moments of yield and total household income (i.e., mean, variance and skewness) using endogenous switching regression models. We report the two stages of our model in Table 2 and Table 3. The choice of variables in the estimation draws from the theoretical and empirical variables in Difalco and Chavas (2009). We first discuss the correlates of SRI adoption, and second we examine the determinants of the mean, variance and skewness for both yield and income. 


\subsection{Determinants of SRI adoption}

Our first step is to shed some light on the observed factors that characterize SRI adopters. We find that wealthier households, and those who rely on agriculture as their main source of income are more likely to adopt SRI. The fact that SRI attracts wealthier farmers is somewhat unexpected given SRI was initially designed to enable poorer farmers to enhance their yields and reduce water consumption. This unexpected pattern in Tanzania is also captured by the fact that farmers using more chemical fertilizers are more willing to adopt this new practice. By contrast, SRI was introduced in Madagascar for farmers who typically could not afford expensive chemical fertilizers and were rather relying on manure and other organic fertilizers. As expected, greater labor supply is a determining factor since SRI is more labor-intensive (extra labor needed for weeding, seed sorting etc.) than the conventional paddy rice farming. Similarly, seed sorting is also associated with SRI adoption. Farmers owning farmland of smaller size, greater soil fertility, and located within close proximity are more eager to adopt SRI. A possible explanation is that, given the recent introduction of SRI, farmers are still experimenting before considering a scale up of this practice. An alternative explanation could be that farmers are simply diversifying their portfolio of technology. It is worth noting that in other settings and regions, farmers have dedicated only relatively small plots to SRI despite its benefits due, among others, to the high opportunity costs this practice is associated with (Moser and Barrett, 2003).

Both formal education (i.e. years of schooling) and extension service based training influence positively the adoption decision, albeit the former tends overall to be statistically less significant. The fact that farmers who receive visits from extension services are more likely to adopt SRI could be due to the complex and un-conventional nature of

SRI. In addition greater social connection (as measured by the number of social groups, and the number of years lived in the village), is associated with technology adoption.

Importantly, we find that changing climatic patterns (as perceived by farmers) influences the decision to adopt SRI. Farmers perceive climatic changes through reduced rainfall and increased temperature. Those who have observed decreasing rainfall patterns are more incline to adopt SRI than those who have not perceived these changes. This suggests that adoption of SRI could be regarded as an adaptation mechanism to climate change since one of its key objectives is to reduce water usage in rice farming. On the other hand, perception of long-term increasing temperatures on SRI adoption is negative but statistically significant only for the mean yield.

We find very similar results for the variance and skewness of the yield. The only two differences is that both education and perceived temperature increase are no longer significant. Finally, the first stage of the income models (Panel $\mathrm{C}$ of Table 3 ) shows very similar results.

\subsection{Switching regression results for mean, variance and skewness of yield and total income}

For an average farmer who has adopted SRI (see Panel A of Table 3), the first three moments of income are primarily influenced by labor supply, plot distance from the homestead, and perception of rising temperature. An increase in these variables results in greater mean income andreduced downside income risk. These positive effects are accompanied with enhanced income variability. Surprisingly, households whose primary activity lies in agriculture experience reduced mean income and increased downside income risk. These adverse effects are however mitigated by the decrease in income variability. It is also noticeable that farmers' experience in rice cultivation reduces income variability while plot size raises it. However, neither variable has a significant effect on expected income or skewness. The results found for rice yield (Panel A of Table 2) are fairly similar although statistical significance is generally more patchy.

Changing climatic conditions as perceived by farmers play a key role in our analysis. In fact, rising temperatures (as perceived by farmers) have a markedly different effect across the group of adopters and non-adopters. Reduced rainfall however does not exhibit such differences. We find that the effect of a rise in temperatures as perceived 
Table 2: Determinants of Yield and SRI: Endogenous Switching Regression Model

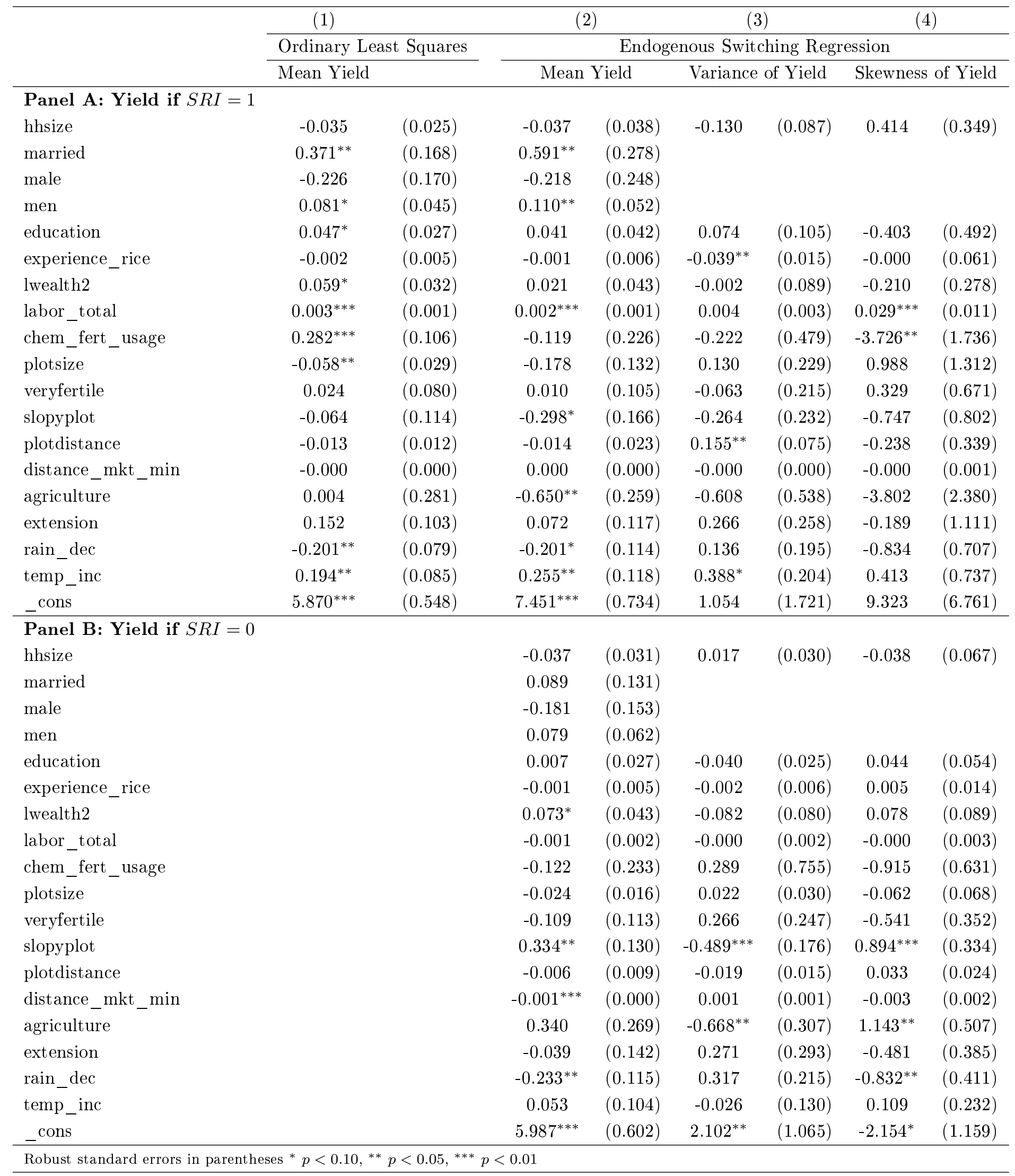




\begin{tabular}{|c|c|c|c|c|c|c|c|}
\hline \multirow{2}{*}{ Panel C: $S R I$ Equation } & \multirow[t]{2}{*}{$\begin{array}{c}(1) \\
\text { Yield OLS }\end{array}$} & $\begin{array}{l}(2 \\
\text { Mean }\end{array}$ & ield & Variance of Yield & $(3)$ & \multicolumn{2}{|c|}{ Skewness of Yield } \\
\hline & & & & & & & \\
\hline hhsize & & 0.102 & $(0.082)$ & 0.135 & $(0.082)$ & $0.150^{* *}$ & $(0.070)$ \\
\hline married & & $0.757^{* *}$ & $(0.372)$ & & & 0.024 & $(0.015)$ \\
\hline male & & $-1.909^{* * *}$ & $(0.546)$ & & & & \\
\hline men & & $0.369^{* *}$ & $(0.187)$ & & & & \\
\hline education & & $0.248^{* *}$ & $(0.099)$ & 0.100 & $(0.077)$ & & \\
\hline experience_rice & & 0.009 & $(0.014)$ & 0.002 & $(0.022)$ & 0.100 & $(0.070)$ \\
\hline lwealth2 & & $0.382^{* * *}$ & $(0.141)$ & $0.312^{* *}$ & $(0.146)$ & $0.271^{* *}$ & $(0.113)$ \\
\hline labor_total & & $0.003^{*}$ & $(0.001)$ & 0.002 & $(0.002)$ & $0.003^{* *}$ & $(0.001)$ \\
\hline chem_fert_usage & & $2.564^{* * *}$ & $(0.389)$ & $2.557^{* * *}$ & $(0.484)$ & $2.390^{* * *}$ & $(0.367)$ \\
\hline plotsize & & $-1.022^{* * *}$ & $(0.293)$ & $-0.914^{* * *}$ & $(0.297)$ & $-0.949^{* *}$ & $(0.412)$ \\
\hline veryfertile & & $0.631^{* *}$ & $(0.307)$ & $0.753^{* *}$ & $(0.347)$ & $0.673^{* *}$ & $(0.289)$ \\
\hline slopyplot & & -0.265 & $(0.446)$ & -0.393 & $(0.377)$ & -0.225 & $(0.338)$ \\
\hline plotdistance & & $-0.087^{* * *}$ & $(0.032)$ & $-0.076^{*}$ & $(0.040)$ & $-0.062^{*}$ & $(0.033)$ \\
\hline distance_mkt_min & & $0.002^{* *}$ & $(0.001)$ & $0.002^{*}$ & $(0.001)$ & $0.002^{*}$ & $(0.001)$ \\
\hline agriculture & & $1.557^{* *}$ & $(0.709)$ & 1.445 & $(1.362)$ & $1.387^{* *}$ & $(0.625)$ \\
\hline extension & & $0.907^{* * *}$ & $(0.310)$ & $0.765^{* *}$ & $(0.332)$ & $0.876^{* * *}$ & $(0.306)$ \\
\hline rain_dec & & $0.815^{* * *}$ & $(0.279)$ & $0.464^{*}$ & $(0.256)$ & $0.465^{* *}$ & $(0.231)$ \\
\hline temp_inc & & $-0.644^{*}$ & $(0.355)$ & -0.444 & $(0.438)$ & -0.345 & $(0.358)$ \\
\hline years_invillage & & $0.031^{* *}$ & $(0.013)$ & $0.041^{* * *}$ & $(0.016)$ & & \\
\hline connected2 & & $1.097^{* *}$ & $(0.466)$ & 1.169 & $(0.845)$ & $1.258^{* * *}$ & $(0.480)$ \\
\hline sortseed & & $1.442^{* * *}$ & $(0.296)$ & $1.093^{* *}$ & $(0.476)$ & $1.015^{* * *}$ & $(0.300)$ \\
\hline _cons & & $-10.323^{* * *}$ & $(2.104)$ & $-9.015^{* * *}$ & $(2.141)$ & $-8.295^{* * *}$ & $(2.073)$ \\
\hline$\sigma_{1}^{2}$ & & $0.787^{* * *}$ & $(0.119)$ & $1.884^{* * *}$ & $(0.215)$ & $7.562^{* * *}$ & $(0.343)$ \\
\hline$\rho_{1 v}$ & & -0.348 & $(0.213)$ & -0.087 & $(0.110)$ & -0.424 & $(0.338)$ \\
\hline$\sigma_{0}^{2}$ & & $0.528^{* * *}$ & $(0.079)$ & $0.783^{* * *}$ & $(0.235)$ & $1.781^{* * *}$ & $(0.268)$ \\
\hline$\rho_{0 v}$ & & -0.473 & $(0.395)$ & 0.414 & $(1.108)$ & $-0.675^{* *}$ & $(0.341)$ \\
\hline Chi Test Indep & & $3.036^{*}$ & & 0.619 & & $3.843^{* *}$ & \\
\hline P-Value Chi test Indep & & 0.081 & & 0.431 & & 0.050 & \\
\hline Admissibility Tests & & & & & & & \\
\hline Chi(3) SRI equation & & $27.99^{* * *}$ & & $24.14^{* * *}$ & & $24.66^{* * *}$ & \\
\hline P-Value Chi test & & 0.000 & & 0.000 & & 0.000 & \\
\hline Chi(3) Outcome equations & & 1.55 & & 3.20 & & 3.46 & \\
\hline P-Value Chi test & & 0.671 & & 0.362 & & 0.177 & \\
\hline Number of Countries & 325 & 325 & & 325 & & 325 & \\
\hline Log Pseudo-Likelihood & -358.624 & -368.002 & & -591.717 & & -958.180 & \\
\hline
\end{tabular}

Robust standard errors in parentheses ${ }^{*} p<0.10,{ }^{* *} p<0.05,{ }^{* * *} p<0.01$ 
Table 3: Determinants of Income and SRI: Endogenous Switching Regression Model

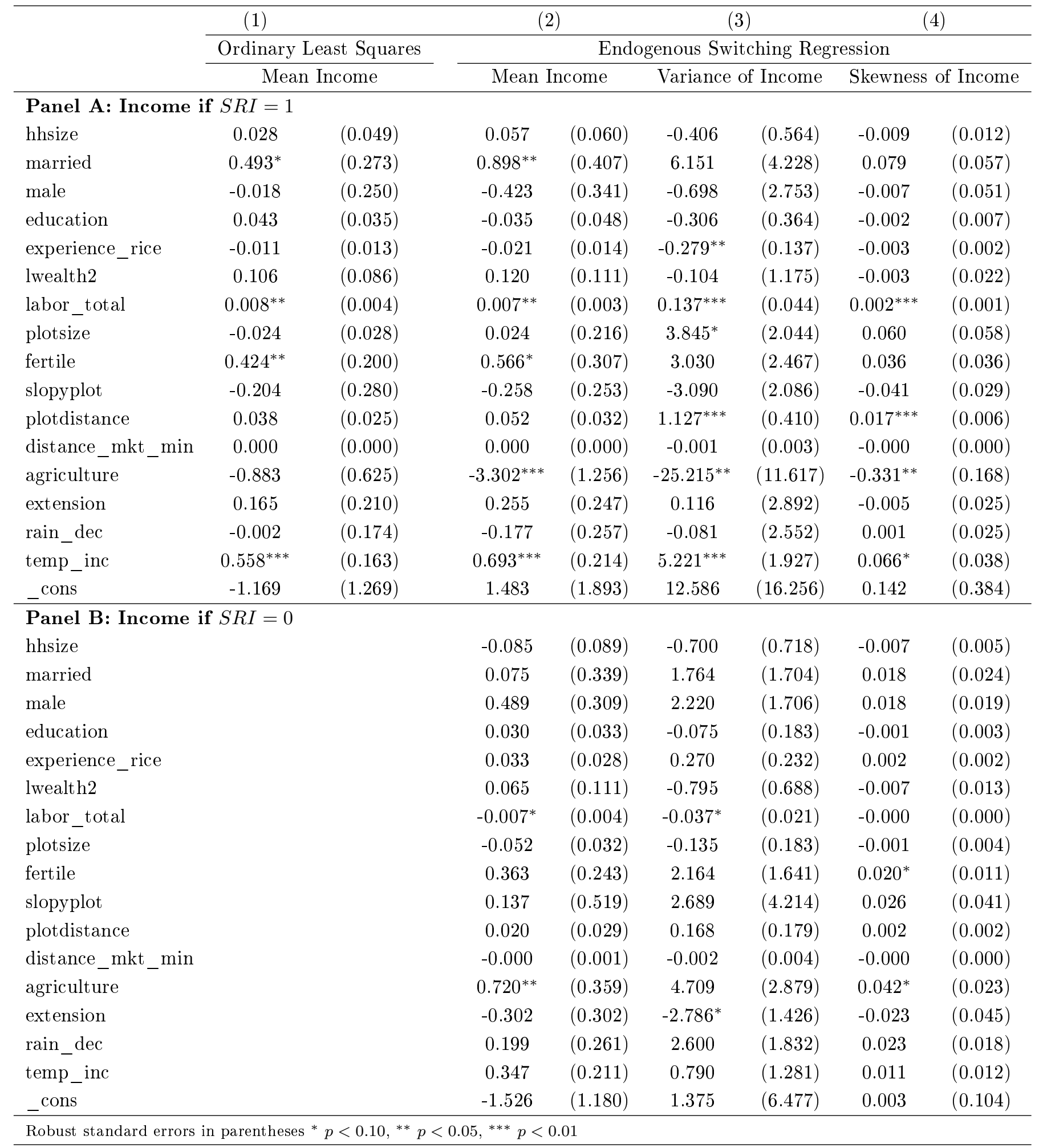




\begin{tabular}{|c|c|c|c|c|c|c|c|}
\hline \multirow{2}{*}{ Panel C: $S R I$ Equation } & \multirow[t]{2}{*}{$\begin{array}{c}(1) \\
\text { Income OLS }\end{array}$} & \multicolumn{2}{|c|}{$(2)$} & \multicolumn{2}{|c|}{$(3)$} & \multicolumn{2}{|c|}{$(4)$} \\
\hline & & & & & & & \\
\hline hhsize & & $0.110^{*}$ & $(0.063)$ & $0.109^{*}$ & $(0.063)$ & $0.109^{*}$ & $(0.065)$ \\
\hline married & & 0.560 & $(0.394)$ & 0.577 & $(0.396)$ & 0.580 & $(0.405)$ \\
\hline male & & $-1.288^{* * *}$ & $(0.448)$ & $-1.276^{* * *}$ & $(0.446)$ & $-1.280^{* * *}$ & $(0.447)$ \\
\hline education & & $0.111^{*}$ & $(0.059)$ & $0.111^{*}$ & $(0.058)$ & $0.112^{*}$ & $(0.058)$ \\
\hline experience_rice & & $0.023^{*}$ & $(0.012)$ & $0.023^{*}$ & $(0.012)$ & $0.023^{*}$ & $(0.013)$ \\
\hline lwealth2 & & $0.252^{* *}$ & $(0.104)$ & $0.248^{* *}$ & $(0.105)$ & $0.249^{* *}$ & $(0.106)$ \\
\hline labor_total & & 0.001 & $(0.001)$ & 0.001 & $(0.001)$ & 0.001 & $(0.001)$ \\
\hline plotsize & & $-1.088^{* * *}$ & $(0.290)$ & $-1.080^{* * *}$ & $(0.288)$ & $-1.083^{* * *}$ & $(0.289)$ \\
\hline fertile & & $1.204^{* * *}$ & $(0.307)$ & $1.189^{* * *}$ & $(0.301)$ & $1.194^{* * *}$ & $(0.303)$ \\
\hline slopyplot & & -0.191 & $(0.269)$ & -0.187 & $(0.267)$ & -0.188 & $(0.268)$ \\
\hline plotdistance & & $-0.053^{* *}$ & $(0.023)$ & $-0.051^{* *}$ & $(0.023)$ & $-0.051^{* *}$ & $(0.024)$ \\
\hline distance_mkt_min & & $0.001^{*}$ & $(0.001)$ & $0.001^{*}$ & $(0.001)$ & $0.001^{*}$ & $(0.001)$ \\
\hline agriculture & & 0.562 & $(0.673)$ & 0.602 & $(0.652)$ & 0.613 & $(0.654)$ \\
\hline extension & & $1.083^{* * *}$ & $(0.235)$ & $1.064^{* * *}$ & $(0.233)$ & $1.072^{* * *}$ & $(0.235)$ \\
\hline rain_dec & & $0.557^{* *}$ & $(0.229)$ & $0.552^{* *}$ & $(0.227)$ & $0.553^{* *}$ & $(0.229)$ \\
\hline temp_inc & & $-0.467^{*}$ & $(0.249)$ & $-0.462^{*}$ & $(0.250)$ & $-0.461^{*}$ & $(0.250)$ \\
\hline connected2 & & $1.222^{* * *}$ & $(0.373)$ & $1.194^{* * *}$ & $(0.370)$ & $1.194^{* * *}$ & $(0.378)$ \\
\hline sortseed & & $1.498^{* * *}$ & $(0.253)$ & $1.515^{* * *}$ & $(0.248)$ & $1.514^{* * *}$ & $(0.250)$ \\
\hline _cons & & $-6.357^{* * *}$ & $(1.676)$ & $-6.350^{* * *}$ & $(1.656)$ & $-6.377^{* * *}$ & $(1.658)$ \\
\hline$\sigma_{1}^{2}$ & & $1.919^{* * *}$ & $(0.197)$ & $22.989^{* * *}$ & $(0.344)$ & 0.358 & $(0.383)$ \\
\hline$\rho_{1 v}$ & & $-0.162^{*}$ & $(0.096)$ & -0.074 & $(0.067)$ & -0.103 & $(0.207)$ \\
\hline$\sigma_{0}^{2}$ & & $1.487^{* * *}$ & $(0.184)$ & $10.483^{* * *}$ & $(0.256)$ & 0.094 & $(0.291)$ \\
\hline$\rho_{0 v}$ & & -0.077 & $(0.293)$ & -0.047 & $(0.205)$ & -0.041 & $(0.691)$ \\
\hline Chi Test Indep & & $2.821^{*}$ & & 1.225 & & 0.249 & \\
\hline P-Value Chi test Indep & & 0.093 & & 0.268 & & 0.617 & \\
\hline Admissibility Tests & & & & & & & \\
\hline Chi Test SRI equation & & $43.66^{* * *}$ & & $50.79^{* * *}$ & & $50.66^{* * *}$ & \\
\hline P-Value Chi test & & 0.000 & & 0.000 & & 0.000 & \\
\hline Chi Test Outcome equations & & 0.21 & & 2.32 & & 4.00 & \\
\hline P-Value Chi test & & 0.646 & & 0.313 & & 0.135 & \\
\hline Number of Countries & 332 & 332 & & 332 & & 332 & \\
\hline Log Pseudo-Likelihood & -672.115 & -735.022 & & -1486.371 & & -27.541 & \\
\hline
\end{tabular}

Robust standard errors in parentheses ${ }^{*} p<0.10,{ }^{* *} p<0.05,{ }^{* * *} p<0.01$ 
by adopting farmers is to raise expected income and expected rice yield, at the expense of increased variability. Downside risk is also reduced although it is statistically significant only for income. By contrast, non-adopting farmers' perception of rising temperatures has no statistically significant effect on any of our dependent variables.

The effect of perceived higher temperature runs entirely through adopting farmers. While farmers are less likely to adopt SRI when they perceive rising temperatures, for those farmers who have indeed adopted SRI, the perception of increasing temperatures is associated with greater expected yield and variability but also with greater expected income, increased income variability and reduced exposure to downside income risk. This overall positive effect of rising in temperature is somewhat counter-intuitive though robust. Indeed, although rice grows linearly in the range of $22-31^{\circ} \mathrm{C}$, higher temperature adversely affects growth and productivity (Yoshida, 1981; Krishnan et al., 2011). However, increase in mean temperature or episodes of high temperatures during sensitive stages of the crop may adversely affect the growth and yield of rice especially in tropical regions where temperatures are often above the optimal for growth $\left(28 / 22^{\circ} \mathrm{C}\right.$, i.e., $28^{\circ} \mathrm{C}$ in daytime and $22^{\circ} \mathrm{C}$ at night $){ }^{7}$ Given that mean temperatures in the Kilimbero district fluctuates between $20.5^{\circ} \mathrm{C}$ and $26.6^{\circ} \mathrm{C}$ in a given year, a rise in temperature would still have positive effect on rice yield.

On the other hand, the perception of reduced precipitation affects negatively the mean yield for SRI adopters, but has no effect on its variance and skewness, nor does it have an impact on the moments of income. For non-adopters however, the perception of reduced precipitation has a negative impact on both expected yield and its skewness but does not affect the moments of income. In brief, farmers who observe reduced rainfall also experience reduced rice yields irrespective of their adoption decision.

Finally, while we can reject the null hypothesis of independent equations the mean income, the mean yield, and the skewness of yield, the LR test cannot reject independence for yield variance, income variance and income skewness. This suggests that the hypothesis of absence of sample selectivity bias may be rjected for the former cases but not for the latter cases.

\subsection{Average treatment effects}

We now present the average treatment effect of adopting SRI (see Table 4). Panel A shows the average treatment effect on the treated (ATT) for the first three moments of rice yield and total income. Panel B in turn presents the average treatment effect on the untreated (ATU). ${ }^{8}$

First of all, we find that SRI adoption has a positive and statistically significant impact on expected yield and expected income. On average, adopters increase their rice production per acre by 13 percent and total income by 83 percent compared to non-adoptors. The impact is economically large and statistically significant at one percent level.

Secondly, we find that adopting SRI raises income variability relative to non-adopters, but has no impact on the variability of rice yield. Thus, risk-averse farmers would likely abstain from adoption, especially with regard to household income. Higher variance of gains from improved agricultural technologies is also documented to be the reason why risk averse farmers are less likely to adopt such technologies (e.g. Yesuf and Bluffston, 2009; Tanaka et al., 2010$)$.

Thirdly, we find that SRI adoption has a positive and statistically significant impact on the skewness of rice yield and total income. The combined effect of increased income variance and skewness suggests that the technology increases income uncertainty but lowers the probability of household exposure to downside income risks. This could explain why, in contrast with the intended goal of opening new opportunities to address the needs of poorer farmers, wealthier farmers (who are less susceptible to risk aversion) have been more willing to adopt SRI. On the other

\footnotetext{
${ }^{7}$ Temperature influences growth rate, duration, and productivity. According to Baker et al. (1992), yield decrease was about 7-8\% in rice for each $1^{\circ} \mathrm{C}$ increase in daytime maximum/nighttime minimum in temperature from $28 / 21^{\circ} \mathrm{C}$ to $34 / 27^{\circ} \mathrm{C}$.

${ }^{8}$ We bootstrap the distribution following Kim and Chavas (2003).
} 
hand, a reduction in exposure to downside risk (combined with increased expected rice yield and income) may neutralize the income risk (due to high variance) and encourage even risk averse farmers to adopt the technology.

Panel B presents the average treatment effects for the untreated (ATU) or equivalently on SRI non-adopters. From a policy perspective, these effects, which broadly accord with the ones discussed above, are highly relevant. Our results show that while non-adopters' expected rice yield and expected income would have increased by $5.5 \%$ and $32 \%$ respectively, had they adopted SRI, the variance of the relevant variables increase by a factor of two and three, respectively. Moreover, downside risk exposure is reduced substantially for yield rice and marginally for income.

Finally, we note that both for those farmers who perceive increased temperatures, average productivity and income gains benefit primarily SRI adopters. Indeed, for SRI adopters, the respective coefficients of perceived temperature increase are positive and significant at the $1 \%$ level for income and $5 \%$ level for yield but insignificant for nonadopters.

Overall, the finding that despite increased yield, increased variance is not offset by reduced downside risk may explain why farmers are reluctant to adopt SRI given "the empirical evidence that most farmers are risk averse (Lin et al., 1974; Binswanger, 1981; Antle, 1987; Saha et al., 1994) as well as downside risk averse (e.g. Binswanger, 1981; Chavas and Holt, 1996)" (See Kim and Chavas, 2003). It should be noted that these results highlight climatic factors have critical role to play in gains from a technological intervention in addition to price (Alem et al., 2015) and phisical farm characteristics (Difalco and Veronsi, 2013). 


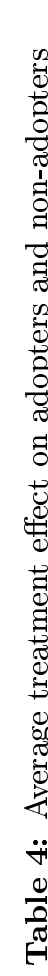

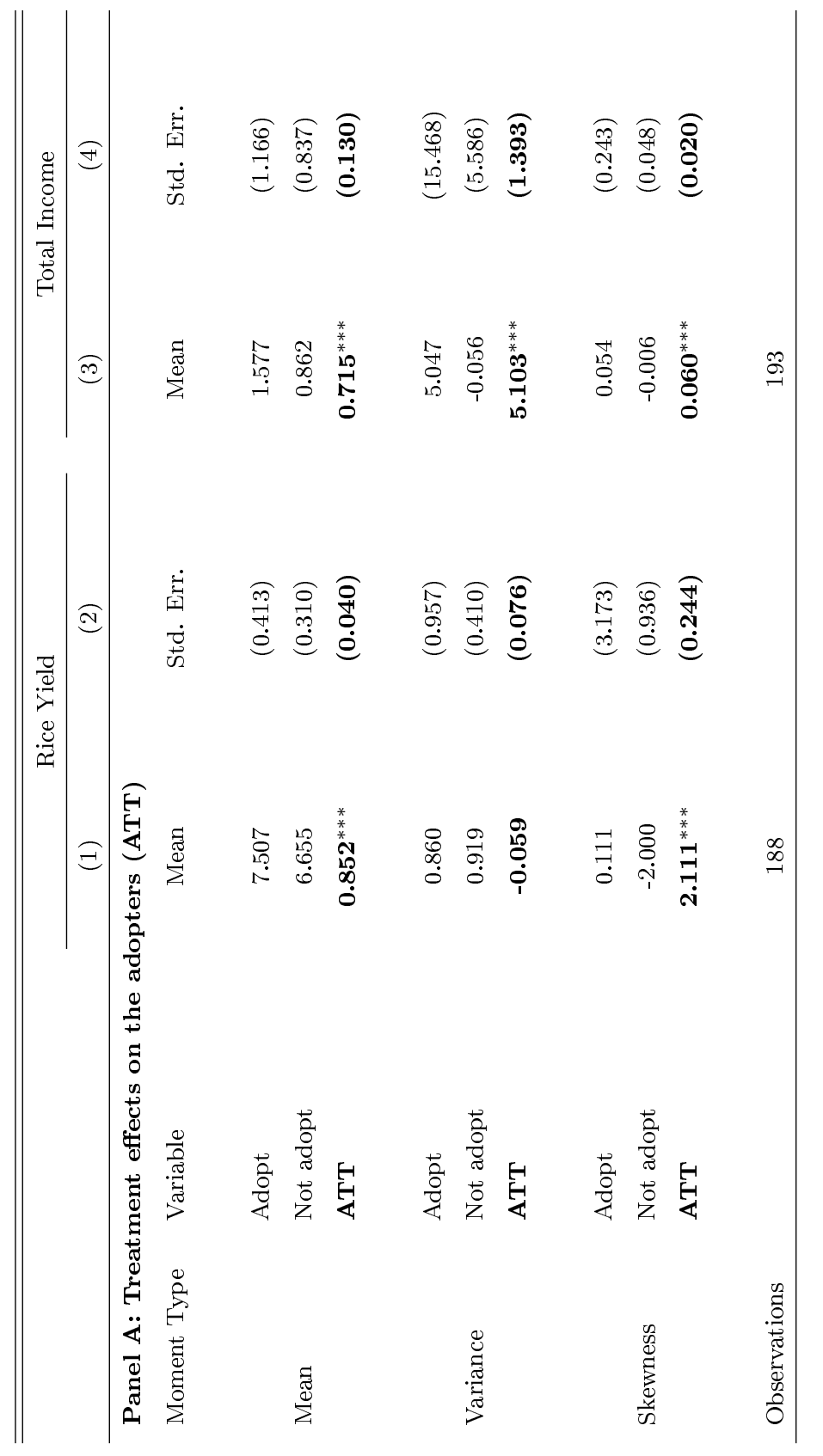

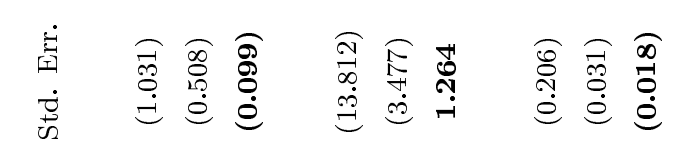

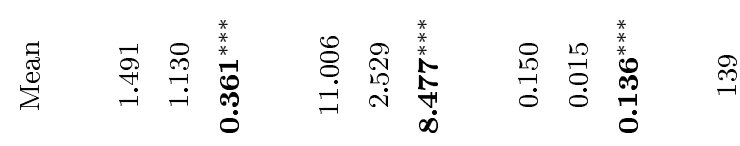

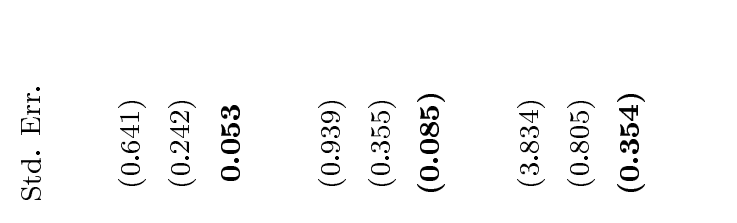

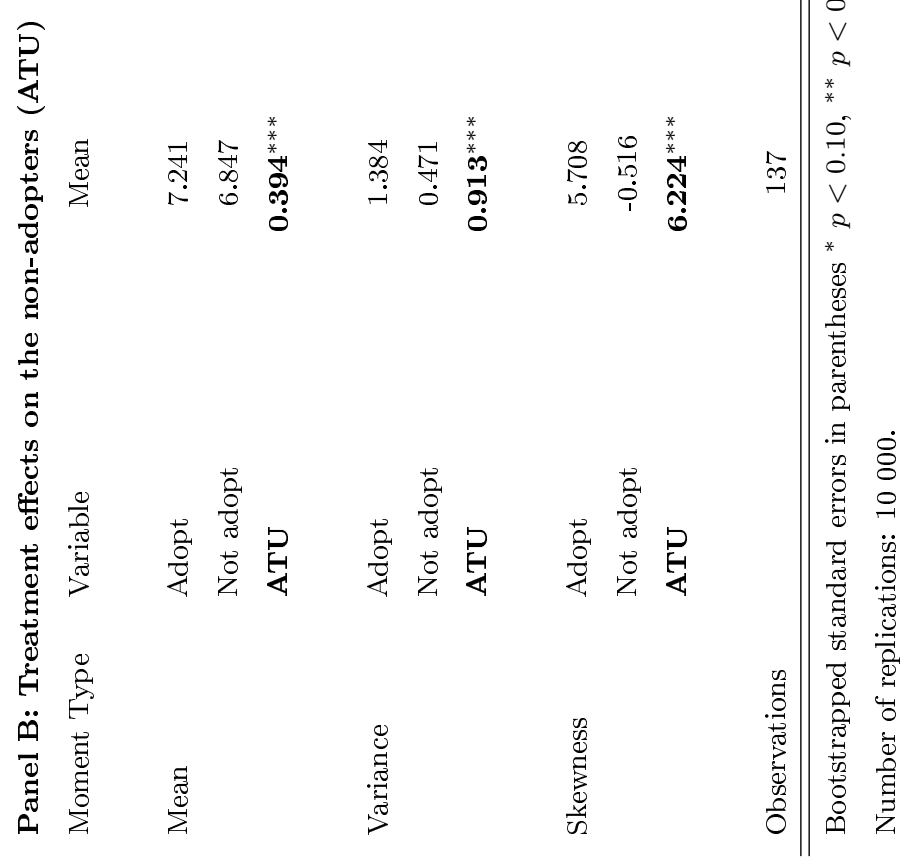




\section{Conclusions}

This paper presents an impact evaluation analysis of the recent introduction of the System of Rice Intensification (SRI) in Morogoro (Tanzania), with a focus on exposure to risk and downside risk of rice yield and total household' income, in addition to mean yield and income. Despite the recentness of the intervention and gaps in the local policy environment, we find evidence of large economic impacts of SRI adoption. Overall, SRI adoption comes with a trade-off between greater expected yields and expected income on the one hand, and increased income variability on the other hand. We also find that SRI has a considerable impact on reducing downside risk, as indicated by the positive and significant coefficients of yield and income skewness. This suggests that the reluctance of risk averse farmers to adopt SRI due to increased income variability may be mitigated by the increase in skewness. These results are obtained using an endogenous switching regression model that estimates jointly the determinants of SRI adoption and the three moments of rice yield and household income. We provide evidence of the importance of wealth, soil fertility, farm size, extension services, social connection and climate change perception in shaping the decision to adopt SRI. The measures of climate risk perception (in particular rising temperatures) are associated with increased yields and income as well as their variance and skewness. Decreased rainfall however is correlated with reduced yields and increased exposure to downside risk.

The results of this study improve our understanding of the behavioral and policy factors that can help understand the constraints to and opportunities in the adoption of new technology. This paper suggests that sufficient awareness of the occurrence of climate change can contribute to reduce downside risk exposure despite increased variance. This provides useful insights on the linkages between climate change perceptions and the income risk impact of new technology. Understanding of the contribution of technologies to yield variability and downside risk goes beyond addressing the risk concerns of producers. Such analyses would also highlight how much and in what ways deliberately incorporating such features into the development of agricultural technologies enhance the overall societal value of the technology (Schuh and Tollini 1979).

One important shortcoming of the analysis is that it is based on cross sectional survey, implying that many of the time-variant variables are only snapshots. Further unmeasured characteristics that are important determinants of adoption and risk factors confound with the observed covariates and the sign and magnitude of the resulting omitted variables bias is unknown. Future studies with panel data features would enable controlling for the effect of such unobserved effects.

Given the potential for rural climate information to support adaptation and management of climate risk, there is a need to make climate information more accurate, accessible, and useful for farmers (Roncoli et al., 2002; Ziervogel et al., 2005; Hansen et al., 2007).

Further, follow-up research to assess risk effects of the program-especially by incorporating objective climate change measures (as opposed to perceptions that we have looked into in this paper), the channels through which specific program effects materialize, the path of their evolution over time, and how benefits are distributed across adopters (given our finding of significant heterogeneity), would be of great interest.

With regards to PRISE, the contribution of the study is considerable. The negative impacts of climate change are arguably most felt by hugely agrarian and rainfed economies of many semi-arid lands. Such vulnerability would naturally underscore the importance of mechanisms that enhance the agricultural sector's capacity to cope better with the adverse climate change impacts. As a technology package, the SRI would have climate change compatible features as it is designed to perform in a moisture stressed setting. Our finding that the SRI perfoms a better risk reducing feature with climate perceptive farmers attests to the role of such technologies in climate-risk prone environments. Hence for PRISE regions, there is a need for policy makers to encourage the development and release of climate-sensitive technologies. 


\section{References}

Adger, W. N., Huq, S., Brown, K., Conway, D., \& Hulme, M. (2003). Adaptation to climate change in the developing world. Progress in development studies, 3(3), 179-195.

Africare, Oxfam America, WWF-ICRISAT Project (2010). More Rice for People, More Water for the Planet. WWF-ICRISAT Project, Hyderabad, India.

Agrawala, S., Moehner, A., Hemp, A., van Aalst, M., Hitz, S., Smith, J., ... \& Mwaipopo, O. U. (2003). Development and climate change in Tanzania: focus on Mount Kilimanjaro. Environment Directorate and Development Cooperation Directorate, Organisation for Economic Cooperation and Development (OECD), Paris.

Ahmed, S. A., Diffenbaugh, N. S., Hertel, T. W., \& Martin, W. J. (2012). Agriculture and trade opportunities for Tanzania: past volatility and future climate change. Review of Development Economics, 16(3), 429-447.

Alem, Y., Bezabih, M., Kassie, M., \& Zikhali, P. (2010). Does fertilizer use respond to rainfall variability? Panel data evidence from Ethiopia. Agricultural Economics, 41(2), 165-175.

Alem, Y., Eggert, H. \& Ruhinduka, R. 2015. Improving Welfare Through Climate-Friendly Agriculture: The Case of the System of Rice Intensification. Environmental and Resource Economics Volume 62, Issue 2, pp 243-263

Amare, M., Asfaw, S., \& Shiferaw, B. (2012). Welfare impacts of maize-pigeonpea intensification in Tanzania. Agricultural Economics, 43(1), 27-43.

Antle, J. M. (1983). Testing the stochastic structure of production: a flexible moment-based approach. Journal of Business \& Economic Statistics, 1(3), 192-201.

Antle, J. M. (1983). Testing the stochastic structure of production: a flexible moment-based approach. Journal of Business \& Economic Statistics, 1(3), 192-201.

Antle, J. M. (1987). Econometric estimation of producers' risk attitudes. American Journal of Agricultural Economics, 69(3), 509-522.

Antle, J. M., \& Crissman, C. C. (1990). Risk, efficiency, and the adoption of modern crop varieties: Evidence from the Philippines. Economic Development and Cultural Change, 517-537.

Antle, J. M., \& Goodger, W. J. (1984). Measuring stochastic technology: the case of Tulare milk production. American Journal of Agricultural Economics, 66(3), 342-350.

Arndt, C., Farmer, W., Strzepek, K., \& Thurlow, J. (2012). Climate change, agriculture and food security in Tanzania. Review of Development Economics, 16(3), 378-393.

Asfaw, S., Kassie, M., Simtowe, F., \& Lipper, L. (2011). Poverty reduction effects of agricultural technology: A micro-evidence from Tanzania. Food and Agricultural Organization of the United Nations, Agricultural Development Economics Division, working paper.

Asfaw, S., Shiferaw, B., Simtowe, F., and Lipper, L. (2012). Impact of modern agricultural technologies on smallholder welfare: Evidence from Tanzania and Ethiopia. Food policy, 37(3):283\{295.

Barrett, C.B., Moser, M.M. , McHugh,V.O. and Barison,J. (2004). "Better Technology, Better Plots or Better Farmers? Identifying Changes In Productivity And Risk Among Malagasy Rice Farmers". American Journal of Agricultural Economics, Vol 86, No.4, pp 869-888.

Binswanger, H. P. (1981). Attitudes toward risk: Theoretical implications of an experiment in rural India. The Economic Journal, 867-890.

Brennan, J. P. (1984). Measuring the contribution of new varieties to increasing wheat yields. Review of Marketing and Agricultural Economics, 52(3), 175-195.

Bryan, E., Deressa, T. T., Gbetibouo, G. A., \& Ringler, C. (2009). Adaptation to climate change in Ethiopia and South Africa: options and constraints. environmental science \& policy, 12(4), 413-426. 
Byerlee, D. (1996). Modern varieties, productivity, and sustainability: Recent experience and emerging challenges. World Development, 24(4), 697-718.

Chavas, J. P. (2004). Risk analysis in theory and practice. Academic Press

Chavas, J. P., \& Holt, M. T. (1996). Economic behavior under uncertainty: A joint analysis of risk preferences and technology. The review of economics and statistics, 329-335.

Christiaensen, L. \& L. Demery (2007). Down to earth: agriculture and poverty reduction in Africa Directions in Development, World Bank.

David, S., Mukandala, L., \& Mafuru, J. (2002). Seed availability, an ignored factor in crop varietal adoption studies: a case study of beans in Tanzania. Journal of Sustainable Agriculture, 21(2), 5-20.

De Janvry, A., \& Sadoulet, E. (2002). World poverty and the role of agricultural technology: direct and indirect effects. Journal of Development Studies, 38(4), 1-26.

Di Falco, S., \& Chavas, J. P. (2009). On crop biodiversity, risk exposure, and food security in the highlands of Ethiopia. American Journal of Agricultural Economics, 91(3), 599-611.

Di Falco, S., Veronesi, M., \& Yesuf, M. (2011). Does adaptation to climate change provide food security? A micro-perspective from Ethiopia. American Journal of Agricultural Economics, 93(3), 829-846.

Di Falco, S, M. Veronesi 2013. How African Agriculture Can Adapt to Climate Change? Countefactual Analysis from Ethiopia. Land Economics. 89 (4): 743-766.

Dinar, A., Hassan, R., Mendelsohn, R., \& Benhin, J. (2012). Climate change and agriculture in Africa: impact assessment and adaptation strategies. Routledge.

Dixon, J., Nalley, L., Kosina, P., La Rovere, R., Hellin, J., \& Aquino, P. (2006). Adoption and economic impact of improved wheat varieties in the developing world. The Journal of Agricultural Science, 144(06), 489-502.

Evenson, R. E., \& Gollin, D. (2003). Assessing the impact of the Green Revolution, 1960 to 2000. Science, 300(5620), 758-762.

Hansen, J. W., Baethgen, W. E., Osgood, D. E., Ceccato, P. N., \& Ngugi, R. K. (2007). Innovations in climate risk management: protecting and building rural livelihoods in a variable and changing climate.

Hillocks, R. J., Madata, C. S., Chirwa, R., Minja, E. M., \& Msolla, S. (2006). Phaseolus bean improvement in Tanzania, 1959-2005. Euphytica, 150(1-2), 215-231.

Howlett, W. P., Brubaker, G. R., Mlingi, N., \& Rosling, H. (1990). Konzo, an epidemic upper motor neuron disease studied in Tanzania. Brain, 113(1), 223-235.

Howe, P. and A. Leiserowitz. 2013. Who remembers a hot summer or a cold winter? The asymmetric effect of beliefs about global warming on perceptions of local climate conditions in the U.S. Global Environmental Change. Volume 23, Issue 6, December 2013, Pages 1488-1500.

Jacoby, H.G (1993), "Shadow Wages and Peasant Family Labor Supply: An Econometric Application to the Peruvian Sierra", The Review of Economic Studies, Vol 60, No.4, pp903-921

Just, R. E., \& Pope, R. D. (1978). Stochastic specification of production functions and economic implications. Journal of Econometrics, 7(1), 67-86.

Just, R. E., \& Pope, R. D. (1979). Production function estimation and related risk considerations. American Journal of Agricultural Economics, 61(2), 276-284.

Kaliba, A. R., Verkuijl, H., \& Mwangi, W. (2000). Factors affecting adoption of improved maize seeds and use of inorganic fertilizer for maize production in the intermediate and lowland zones of Tanzania. Journal of Agricultural and Applied Economics, 32(1), 35-48.

Katambara, Z., Kahimba, F. C., Mahoo, H. F., Mbungu, W. B., Mhenga, F., Reuben, P., \& Nyarubamba, A. (2013a). Adopting the system of rice intensification (SRI) in Tanzania: A review. Agricultural Sciences, 2013. 
Katambara, Z., Kahimba, F. C., Mbungu, W. B., Reuben, P., Maugo, M., Mhenga, F. D., \& Mahoo, H. F. (2013b). Optimizing System of Rice Intensification Parameters Using Aquacrop Model for Increasing Water Productivity and Water Use Efficiency on Rice Production in Tanzania. Journal of Agriculture and Sustainability, 4(2).

Kathage, J., Qaim, M., Kassie, M., \& Shiferaw, B. A. (2012). Seed market liberalization, hybrid maize adoption, and impacts on smallholder farmers in Tanzania (No. 12). GlobalFood Discussion Papers.

Kato, Y., Okami, M., \& Katsura, K. (2009). Yield potential and water use efficiency of aerobic rice (Oryza sativa L.) in Japan. Field Crops Research, 113(3), 328-334.

Kim, K., \& Chavas, J. P. (2003). Technological change and risk management: an application to the economics of corn production. Agricultural economics, 29(2), 125-142.

Koundouri, P., Nauges, C., \& Tzouvelekas, V. (2006). Technology adoption under production uncertainty: theory and application to irrigation technology. American Journal of Agricultural Economics, 88(3), 657-670.

Krishnan, P., Ramakrishnan, B., Raja Reddy, K. and Reddy, V.R., 2011. 3 High-Temperature Effects on Rice Growth, Yield, and Grain Quality. Advances in Agronomy, 111: 87-206

Kurukulasuriya, P., Mendelsohn, R., Hassan, R., Benhin, J., Deressa, T., Diop, M., \& Dinar, A. (2006). Will African agriculture survive climate change?. The World Bank Economic Review, 20(3), 367-388.

Lin, W., Dean, G. W., \& Moore, C. V. (1974). An empirical test of utility vs. profit maximization in agricultural production. American Journal of Agricultural Economics, 56(3), 497-508.

Loss, S. P., and Siddique, K. H. M. (1994). Morphological and physiological traits associated with wheat yield increases in Mediterranean environments. Adv.Agron., 52, 229-276.

Maddison, D. J. (2007). The perception of and adaptation to climate change in Africa. World Bank Policy Research Working Paper, (4308).

Mahoo, H, M. Young, and O. Mzirai (1999) Rainfall Variability and its Implications for the Transferability of Experimental ,Results in the Semi Arid Areas of Tanzania u. Tanzania Journal of Agricultural Sciences.vol 2(2):127140.

Menezes, C., Geiss, C., \& Tressler, J. (1980). Increasing downside risk. The American Economic Review, 921-932. Mongi, H., Majule, A. E., \& Lyimo, J. G. (2010). Vulnerability and adaptation of rain fed agriculture to climate change and variability in semi-arid Tanzania. African Journal of Environmental Science and Technology, 4(6).

Monyo, E. S., Mgonja, M. A., Ngereza, J. A., \& Rohrbach, D. D. (2002). Adoption of improved sorghum and pearl millet varieties in Tanzania. International Sorghum and Millets Newsletter, 43, 12-14.

Morris, M. L., Tripp, R., \& Dankyi, A. A. (1999). Adoption and Impacts of Improved maize production technology. A case study of the Ghana Grains Development Project. Economic Programme paper, 99-101.

Moser, C. M., \& Barrett, C. B. (2003). The disappointing adoption dynamics of a yield-increasing, low externalinput technology: the case of SRI in Madagascar. Agricultural Systems, 76(3), 1085-1100.

Mwanga, J., Mwangi, W. M., Verkuijl, H., Verkuijl, H., \& Mussei, A. (1999). Adoption of improved wheat technologies by small scale farmers in Mbeya District of Southern Highlands, Tanzania.

Nakano, Y., Tanaka, Y., \& Otsuka, K. (2014). Can "Contract Farming" Increase Productivity of Small-Scale Cultivation in A Rain-fed Area in Tanzania?.

Nkonya, E., Schroeder, T., \& Norman, D. (1997). Factors affecting adoption of improved maize seed and fertiliser in northern Tanzania. Journal of Agricultural Economics, 48(1-3), 1-12.

Noltze,M, Schwarze.S and Qaim. M (2013), "Impacts of natural resource management technologies on agricultural yield and household income: The system of rice intensification in Timor Leste", Ecological Economics, Vol 85, pp. $59-68$

Pecetti, L., Damania, A. B., \& Kashour, G. (1992). Geographic variation for spike and grain characteristics in durum wheat germplasm adapted to dryland conditions. Genetic resources and crop evolution, 39(2), 97-105. 
Pratt, J. W. (1964). Risk aversion in the small and in the large. Econometrica: Journal of the Econometric Society, 122-136.

Roncoli, C., Ingram, K., \& Kirshen, P. (2001). The costs and risks of coping with drought: livelihood impacts and farmers' responses in Burkina Faso. Climate Research, 19(2), 119-132.

Roncoli, C., Ingram, K., \& Kirshen, P. (2002). Reading the rains: Local knowledge and rainfall forecasting in Burkina Faso. Society \&Natural Resources, 15(5), 409-427.

Rowhani, P., Lobell, D. B., Linderman, M., \& Ramankutty, N. (2011). Climate variability and crop production in Tanzania. Agricultural and Forest Meteorology, 151(4), 449-460.

Saha, A., Shumway, C. R., \& Talpaz, H. (1994). Joint estimation of risk preference structure and technology using expo-power utility. American Journal of Agricultural Economics, 76(2), 173-184.

Schuh, G. E., \& Tollini, H. (1979). Costs and benefits of agricultural research: The state of the arts. Washington, DC: World Bank.

Shankar, B., Bennett, R., \& Morse, S. (2007). Output risk aspects of genetically modified crop technology in South Africa. Economics of Innovation and New Technology, 16(4), 277-291.

Shiferaw, B. A., Kebede, T. A., \& You, L. (2008). Technology adoption under seed access constraints and the economic impacts of improved pigeonpea varieties in Tanzania. Agricultural Economics, 39(3), 309-323.

Smale, M., Crossa, J., Del Toro, E., Dubin, J., Fischer, T., Fox, P., ... \& Ward, R. (1996). Understanding global trends in the use of wheat diversity and international flows of wheat genetic resources. Mexico: CIMMYT.

Smit, B., Burton, I., Klein, R. J., \& Wandel, J. (2000). An anatomy of adaptation to climate change and variability. Climatic change, 45(1), 223-251.

Smithers, J., \& Smit, B. (1997). Human adaptation to climatic variability and change. Global Environmental Change, 7(2), 129-146.

Solomon, S., Qin, D., Manning, M., Chen, Z., Marquis, M., Averyt, K. B., ... \& Miller, H. L. (2007). IPCC, 2007: summary for policymakers. Climate change, 93-129.

Stoop, W. A., Uphoff, N., \& Kassam, A. (2002). A review of agricultural research issues raised by the system of rice intensification (SRI) from Madagascar: opportunities for improving farming systems for resource-poor farmers. Agricultural systems, 71(3), 249-274.

Takahashi, K and Barrett, C (2013), "The System of Rice Intensification and Its Impacts on Household Income and Child Schooling:Evidence from Rural Indonesia", American Journal of Agricultural Economis, 96(1), pp269-289

Tanaka.T, Camerer,C.F and Nguyen. Q (2010) "Risk and Time Preferences: Linking Experimental and Household Survey Data from Vietnam" American Economic Review, 100:1, 557-571

Teklewold, Hailemariam, Alemu Mekonnen, Gunnar Kohlin and Salvatore Di Falco. 2015. Does adoption of multiple climate smart practices improve climate resilience of farmers? Empirical evidence from the Nile Basin of Ethiopia.Mimeo. Environment for Development Initiative.

Thomas, D. S., Twyman, C., Osbahr, H., \& Hewitson, B. (2007). Adaptation to climate change and variability: farmer responses to intra-seasonal precipitation trends in South Africa. Climatic change, 83(3), 301-322.

Toenniessen, G., Adesina, A., \& DeVries, J. (2008). Building an alliance for a green revolution in Africa. Annals of the New York Academy of Sciences, 1136(1), 233-242.

Uphoff, N. (2006). The system of rice intensification (SRI) as a methodology for reducing water requirements in irrigated rice production. Paper for International Dialogue on Rice and Water: Exploring Options for Food Security and Sustainable Environments, held at IRRI, Los Baños, Philippines, 241-278.

Vogel, C., \& O Brien, K. (2006). Who can eat information? Examining the effectiveness of seasonal climate forecasts and regional climate-risk management strategies. Climate Research, 33(1), 111.

Weber, Elke. (2010)"What shapes perceptions of climate change?" Climate Change 1(3): 332-342. 
Whitmarsh, L. (2011). Scepticism and uncertainty about climate change: dimensions, determinants and change over time. Mimeo. Cardiff University.

Yesuf, M., \& Bluffstone, R. A. (2009). Poverty, risk aversion, and path dependence in low-income countries: Experimental evidence from Ethiopia. American Journal of Agricultural Economics, 91(4), 1022-1037.

Ziervogel, G., Bithell, M., Washington, R., \& Downing, T. (2005). Agent-based social simulation: a method for assessing the impact of seasonal climate forecast applications among smallholder farmers. Agricultural Systems, $83(1), 1-26$. 